\title{
Multiple unilateral sinus mucoceles: a case report
}

\begin{abstract}
Background: Mucoceles are epithelium lined cystic masses with accumulation of mucoid secretions and desquamated epithelium within the sinus. These are benign lesions causing expansion of the paranasal sinuses. Mucocles are most commonly found in the frontal sinus followed by the ethmoid sinus. Maxillary and sphenoid sinus muoceles are rare.

Case presentation: We report a case of 22years old male who presented to our outpatient department with complaints of bilateral nasal obstruction predominantly on the right side with occasional frontal headache. He also complained of right sided facial pain and heaviness with periorbital pain on the same side. Based on clinical findings and imaging, the most likely diagnosis was two separate ethmoid and frontal mucoceles with pansinusitis, which was confirmed endoscopically intraoperatively and was marsupialized.

Conclusion: Mucoceles can occur as primary lesions or appear as secondary to some other conditions which might be missed on Computed tomography imaging, hence it is important to completely marsupialize and drain the mucoceles to look for the presence of secondary mucoceles. Mucocele are prone to recurrence if not managed adequately. A number of surgical treatment options are available but endoscopic drainage stands as the treatment of choice in majority of the cases as it offers a conservative minimally invasive treatment avoiding inconveniences of different external approaches such as recurrence, post operative morbidity.
\end{abstract}

Keywords: mucocele, frontal sinus, ethmoid sinus, endoscopy
Volume 10 Issue I - 2018

\author{
Vishakha Rane, Haritosh K Velankar, Merin \\ Sara Mathew , Yogesh Dabholkar \\ DY Patil University, India
}

Correspondence: Vishakha Rane, DY Patil University, 50I, Osia Corner Mhatarpada road,Amboli,Andheri- west Mumbai-400058 Maharashtra, India, Tel +9198338155II, Email vishrane.vr@gmail.com

Received: December 0I, 2017 | Published: February 07, 2018

\section{Introduction}

Mucocele of paranasal sinuses is a clinical entity which was first described by Langenbeck in 1820 under the name of hydatis. First histopathological description of mucocele was made by Onodi in 1901. Rollet suggested the name mucocele in 1909. In 1955, Lambert defined fronto-ethmoidal mucoceles as the most common nasal condition to cause proptosis. ${ }^{1}$ Mucocele of a paranasa lsinus is an accumulation of mucoid secretion and desquamated epithelium within the sinus with distension of its walls. These are cyst like expansile and destructive lesions. However, the mucoceles behave like real spaceoccupying lesions that cause bone erosion and the displacement of surrounding structures. The proximity of mucoceles to the brain may cause morbidity and potential mortality, if left without intervention. ${ }^{2}$ It is a relatively uncommon condition. Paranasal sinus mucoceles are most commonly found in the frontal sinus followed by the ethmoid sinus. Maxillary and sphenoid sinus mucoceles are rare. Mucoceles usually enlarge slowly over many years and frequently need ten years or more to become symptomatic. ${ }^{3}$ Endoscopic approach is ideal in mucoceles which can be accessed and widely marsupalised. ${ }^{4}$ In this case report also our patient had two different mucoceles in left frontal and ethmoid sinuses. The diagnosis of which was established based on the history, physical examination, and radiologic findings.

\section{Case report}

A 22years old male presented with bilateral blocked nose sensation (right>left) since 7-8months, persistent frontal headache. History of right sided facial heaviness and pain with right periorbital swelling. No history of trauma, clear fluid discharge from nose. No history of recurrent episodes of upper respiratory tract infections/ recurrent episodes of sneezing/running nose or any previous trauma. On examination, anterior rhinoscopy showed mucopurulent discharge and crusting, nasal endoscopy showed bilateral inferior turbinate hypertrophy, mucosa was normal. CT scans of paranasal sinuses showed large homogenous expansile cystic lesion obstructing the right frontal sinus drainage. Another homogenous mass was noted in extending to the right ethmoid sinus suggesting the possible diagnosis of two separate frontal and ethmoid mucoceles with pansinusitis and right sided proptosis (Figure 1-3).

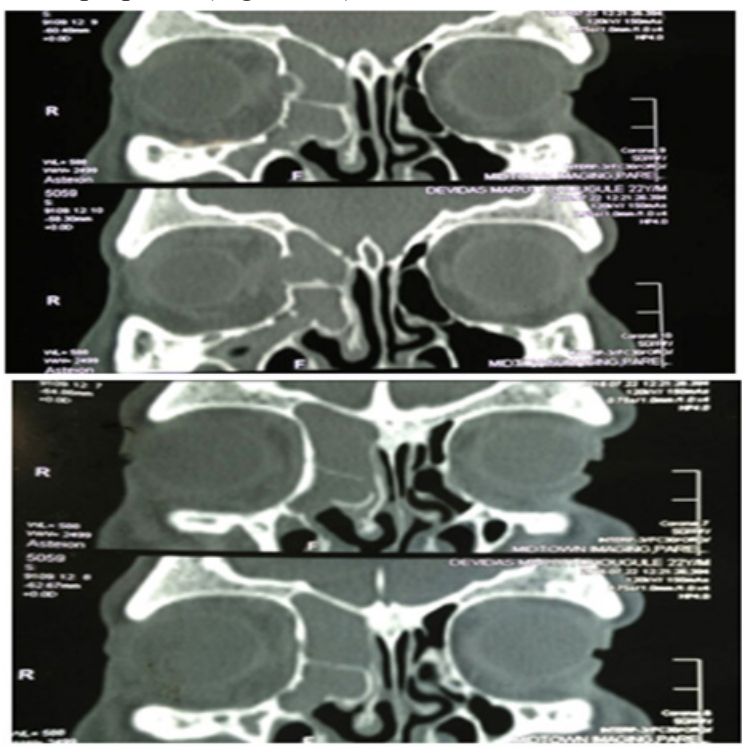

Figure I \& 2 CT scans showing homogenous masses in the right frontal and ethmoid sinuses.

The patient was posted for endoscopic marsupialization of the mucoceles. The mucocele sac from ethmoid sinus was incised and the mucus was drained out (Figure 4 \& 5) following which another mucocele sac was identified in the frontal sinus and was drained out (Figure $6 \& 7$ ) thus confirming the diagnosis of multiple mucocele introperately. 


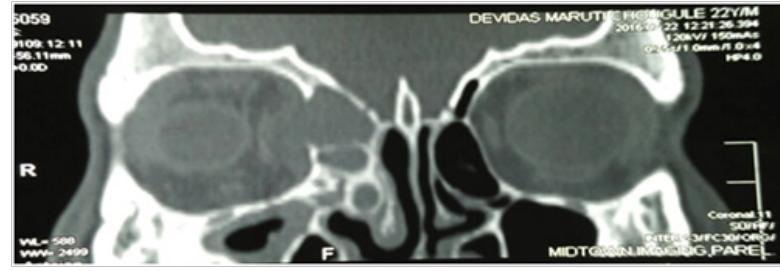

Figure 3 CT scan suggestive of right side proptosis.
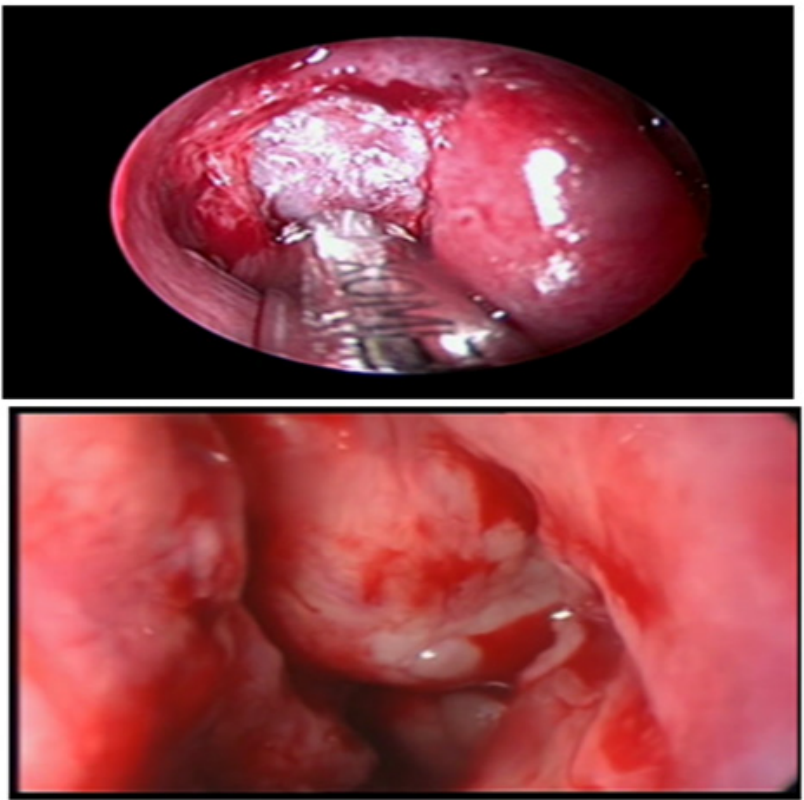

Figure 4 Intraoperative picture showing right ethmoidal mucocele.

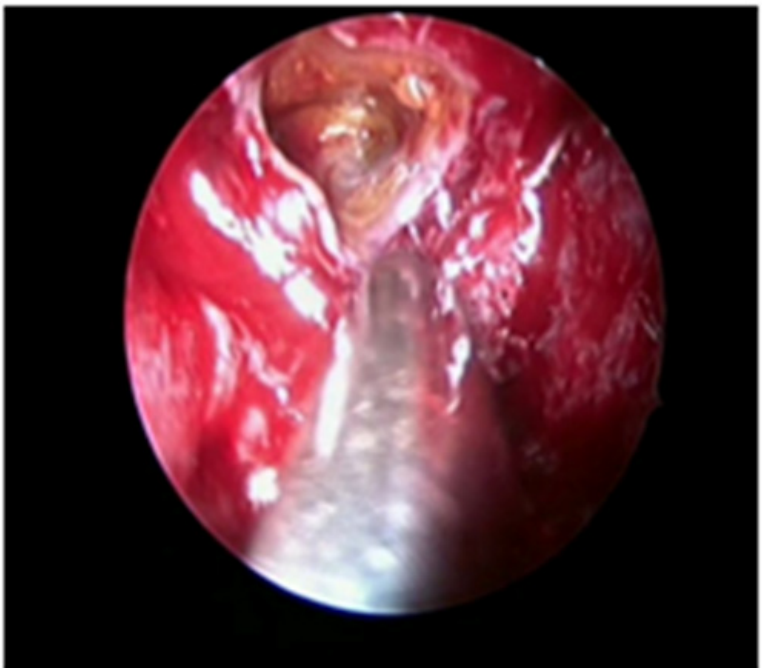

Figure 5 Intraoperative picture taken after draining right ethmoidal mucocele.

Cleared frontal and ethoidal sinuses were examined thoroughly after drainage of the mucoceles (Figure 8). The patient symptoms were relieved postoperatively and the patient was discharged. On follow-up nasal endoscopy showed open sinus cavity, mucosa normal with healthy epithelialization without any sign of recurrence.

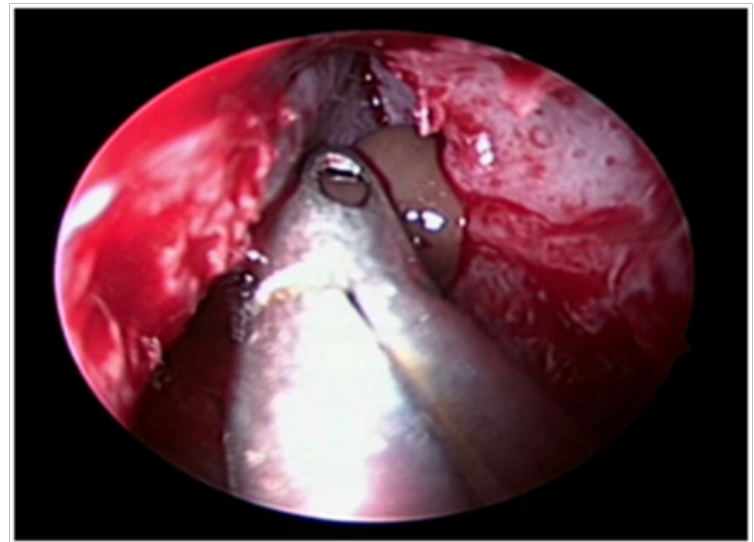

Figure 6 Intraoperative picture showing right frontal mucocele mucocele.

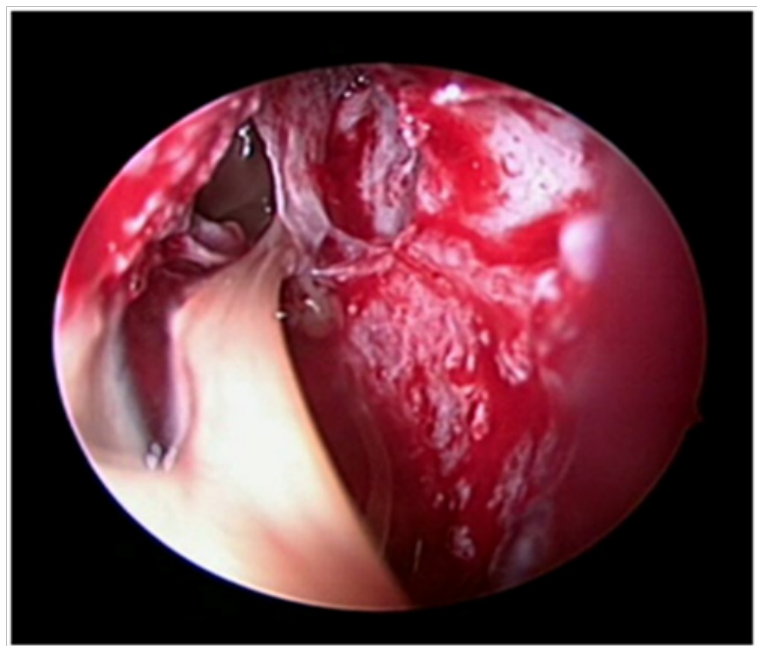

Figure 7 Intraoperative picture showing right frontal sinus after draining frontal.

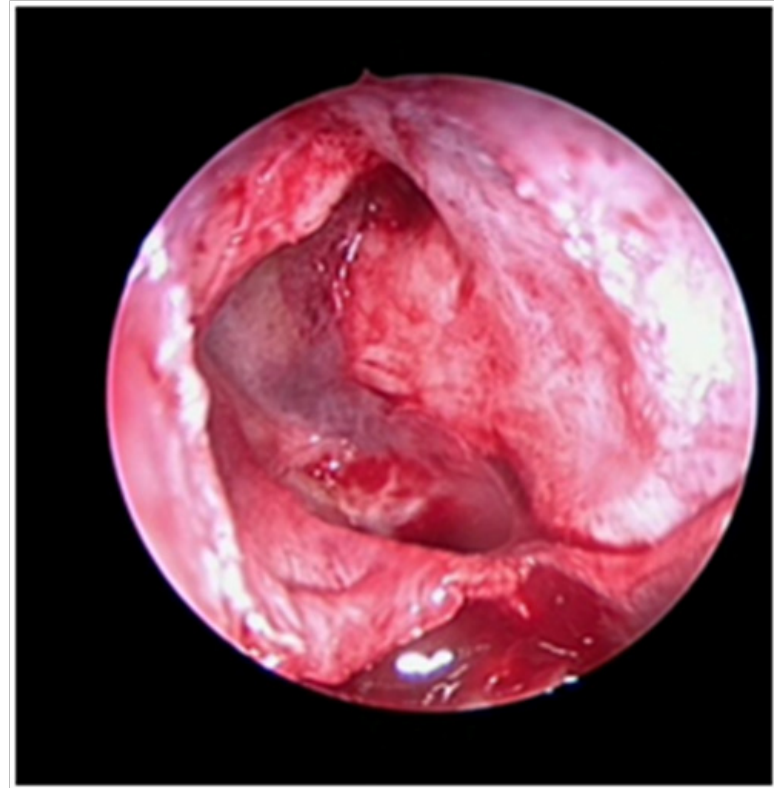

Figure 8 Intraoperative picture showing cleared ethoid and frontal sinuses.

Citation: Hafizi E, Bardhi G. Our experience using HDR brachytherapy for cervical cancer in Albania.J Otolaryngol ENT Res. 20 I8; I0(I):I I-I2. DOI: 10.15406/joentr.2018.10.00300 


\section{Discussion}

Mucocele is defined as benign mucous filled sac lined by epithelium which are slow growing expansile cystic lesion which may be sometimes filled with mucopurulent secreations. ${ }^{5}$ At times associated bone destruction may also be evident. ${ }^{6}$ Mucoceles are rare sinus pathologies; they most commonly involve the ethmoid and frontal sinuses ${ }^{4}$. The etiological factors causing mucoceles are obstruction to drainage channel (natural ostia) of paranasal sinuses, inflammation, allergy, craniofacial trauma, anatomical abnormalities, previous surgeries, sinonasal polypsis, osteomas/ossifying fibromas/ bone fibrous dysplasia, Obstruction of minor salivary glands within linning of paranasal sinuses. The clinical presentation of mucoceles varies with their location. The onset of symptoms is insidious. Patients with fronto-ethmoidal mucoceles may develop frontal headache, visual disturbances like diplopia, facial pain, facial edema, nasal blockage, decreased vision, proptosis, restricted eye movements.

During acute infection of mucoceles leading to mucopyoceles, there is a higher chance of intraorbital and intracranial complications. Intracranial extension through erosion of posterior wall of frontal sinus may lead to meningitis or CSF fistula.

Diagnosis of mucoceles is made on the basis of history, clinical findings, Computed tomography scan (CT scan) or Magnetic resonance imaging (MRI Scan). CT scans are used to determine the anatomy and extent of the lesion. The criterias to diagnose mucocele on the basis of CTscans are-homogenous isodense mass, clearly defined margins and patchy osteolysis around the mass ${ }^{7,8}$ while MRI is used to distinguish between mucoceles and neoplasms.

The treatment of mucocele is surgical. Surgical approaches are based on the size, location and extent of the mucocele. In presence of active infection adjuvant antibiotic treatment is indicated. The route of surgical access may be external or endonasal.

External approach is through frontoethmoidectomy (Lynch's procedure) or by osteoplastic flaps with or without frontal sinus obliteration and total excision of mucosa. ${ }^{9,10}$ These surgeries were the only alternative previously for treatment of mucoceles for many years. These are aggressive procedures with high morbidity and currently only used for extreme cases with significant intracranial and intraorbital extension. ${ }^{11,12}$

Endoscopic approach which are little invasive and have low morbidity are the preferred method now a days as preservation of frontal sinus mucosa and maintenance of patent frontal recess result in a better clinical outcome ${ }^{13}$. Functional endoscopic sinus surgery (FESS) is a conservative minimally invasive method of treatment. However, presence of any sinonasal involvement preventing drainage of the ostium eg. Osteoma or onset of mucocele from the most external and posterosuperior region of the sinus or presence of major sclerosis on the floor of the sinus can be a contradiction for the same.

A combined external and endoscopic approach are used in more severe cases where the anatomy, extent of disease or previous surgery restricts endoscopic visualization and access to the frontal sinus as well as in cases where a fistulous tract is already present.

The aim of surgery is to drain the mucocele and ventilate the sinus involved along with eradication of the mucocele with minimal morbidity and preventin of recurrences. ${ }^{14}$ One should also remember that surgery during acute infection or presence of multiple mucoceles or even significant extension outside the sinus wall can be a risk factor for recurrence.

\section{Conclusion}

Mucoceles are benign lesions of expansile characteristic that may cause severe intraorbital and intracranial complications, if not timely diagnosed and treated. There are two modes of surgical treatment-external approach such as Lynch-Howarth external frontoethmoidectomy or frontal osteoplastic operation. The second method is endoscopic marsupialisation and creation of a new drainage pathway. Functional endoscopic sinus surgery is the trending method used for the treatment of mucoceles. The possibility of multiple unilateral mucoceles should be considered if CTscans reveal large homogenous mass obstructing the ostia of other paranasal sinuses. Thus making it important to look for any secondary mucoceles and marsupialise them. As in our case we came across ethmoid as well as frontal mucoceles.

\section{Acknowledgements}

None.

\section{Conflicts of interest}

Author declares there are no conflicts of interst.

\section{Funding}

None.

\section{References}

1. Alberti PW, Marshall HF, Black Ji. Fronto-ethmoidal mucoceles as a cause of unilateral proptosis. Br J Ophthalmol . 1968;52(11):833-838.

2. Weitzel EK, Hollier LH, Calzada G, et al. Single stage management of complex fronto-orbital mucoceles. $J$ Craniofac surg. 2002;13(6):739-745.

3. Galie M, Mandrioli S, Tieghi R, et al. Giant mucocele of the frontal sinus. J Craniofac surg. 2005;16(5):933-935.

4. Evans C. Aetiology and treatment of fronto-thmoidalmucocele. $J$ Laryngol Otol . 1981;95:361-375.

5. Rubin JS, Lund VJ, Salmon B. Frontoethmoidectomy in the treatment of mucoceles: A neglected operation. Arch Otolaryngol Head Neck Surg . 1986;112: 434-436.

6. Chiarini L, Nocini PF, Bedogni A, et al. Intracranial spread of a giant frontal mucocele: case report.British Journal of Oral \& Maxillofacial Surgery. 2000;38(6): 637-640.

7. Benninger MS, Steven M. The endoscopic management of sphenoid and ethmoid mucoceles with orbital and intranasal extension. Rhinology . 1995;33(3):157-161.

8. Natvig K, Larsen TE. Mucoceles of the paranasal sinus. J Laryngol Otol. 1982;92:1075-1082.

9. Tan CS, Yong VK, Yip LW, et al. An unusual presentation of a giant frontal sinus mucocele manifesting with a subcutaneous forehead mass. ann Acad Med Singapore . 2005;34(5):397-398.

10. Hurley DB1, Javer AR, Kuhn FA, et al. The endoscopic management of chronic frontal sinusitis associated with frontal sinus posterior table erosion. Am J Otolaryngol. 2000;14(2):113-120.

11. Lund VJ, Mucoceles. In: Gleeson M, et al. (Eds.), Scott-Brown's Otorhinolaryngology, Head and Neck Surgery. ( $7^{\text {th }}$ edn), HodderArnold, UK. 2000.

12. Kuhn FA, Javer AR. Primary endoscopic management of the frontal sinus.Otolaryngol Clin North Am. 2001;34:59-75.

13. Edelman RR, Hesselink JR, Zlatkin MB, et al. Clinical Magnetic Resonance Imaging. Philadelphia: Elsevier. 2006. p.2035-2037.

14. Ulualp SO, CarlsonTK, Toohill RJ. Osteoplastic flap versus modified endoscopic Lothrop procedure in patients with frontal sinus disease. $\mathrm{Am}$ J Rhinology. 2000;14(1):21-26. 